\title{
Direct Visualization of a Mechanochemically Induced Molecular Rearrangement
}

\author{
Karen J. Ardila-Fierro, Stipe Lukin, Martin Etter, Krunoslav Užarević, Ivan Halasz, \\ Carsten Bolm, and José G. Hernández*
}

\begin{abstract}
Recent progress in the field of mechanochemistry has expanded the discovery of mechanically induced chemical transformations to several areas of science. However, a general fundamental understanding of how mechanochemical reactions by ball milling occur has remained unreached. For this, we have now implemented in situ monitoring of a mechanochemically induced molecular rearrangement by synchrotron $X$-ray powder diffraction, Raman spectroscopy, and real-time temperature sensing. The results of this study demonstrate that molecular rearrangements can be accomplished in the solid state by ball milling and how in situ monitoring techniques enable the visualization of changes occurring at the exact instant of a molecular migration. The mechanochemical benzil-benzilic acid rearrangement is the focal point of the study.
\end{abstract}

In mechanochemical reactions by ball milling, collisions of accelerated balls inside a milling container maintain a constant mixing of the reactants while simultaneously transducing the energy required to induce specific physicochemical changes into the milled system. The simplicity of this approach has resulted in a growing popularity of ball-milling techniques and their rapid implementation across several areas of chemistry. ${ }^{[1]}$ Such an increase in studies has led to the development of numerous solvent-free variants of known chemical transformations, the discovery of unprecedented chemical reactivity, and the isolation of intermediates not observable from other synthetic approaches. ${ }^{[1 \mathrm{j}, \mathrm{k}]}$ However, a general understanding of how the exertion of mechanical force triggers molecular events in reactants is still to be improved. $^{[2]}$ For addressing these issues, the recent implementation of in situ monitoring techniques to study mechanochemical reactions in standard ball-milling setups ${ }^{[3]}$ has enabled a better comprehension of the pathways leading to the rupture and formation of covalent bonds in a handful of organic transformations (for example, condensations ${ }^{[4]}$ and

[*] Dr. K. J. Ardila-Fierro, Prof. Dr. C. Bolm, Dr. J. G. Hernández Institute of Organic Chemistry, RWTH Aachen University Landoltweg 1, 52074 Aachen (Germany)

E-mail: jose.hernandez@oc.rwth-aachen.de

Dr. S. Lukin, Dr. K. Užarević, Dr. I. Halasz

Division of Physical Chemistry, Ruđer Bošković Institute

Bijenička 54, 10000 Zagreb (Croatia)

Dr. M. Etter

Deutsches Elektronen-Synchrotron (DESY)

Notkestr. 85, 22607 Hamburg (Germany)

(6) Supporting information and the ORCID identification number(s) for

iD the author(s) of this article can be found under:

https://doi.org/10.1002/anie.201914921. (thio)acylations ${ }^{[5]}$ ). In this context, we became curious as to whether a combination of in situ real-time monitoring by synchrotron powder X-ray diffraction (PXRD), Raman spectroscopy, and temperature sensing could be applied for the investigation of a fundamentally different type of organic reaction; namely, a molecular rearrangement. As the first example, we considered the emblematic benzil-benzilic acid rearrangement in the presence of hydroxide ions (Scheme 1a).

(a)
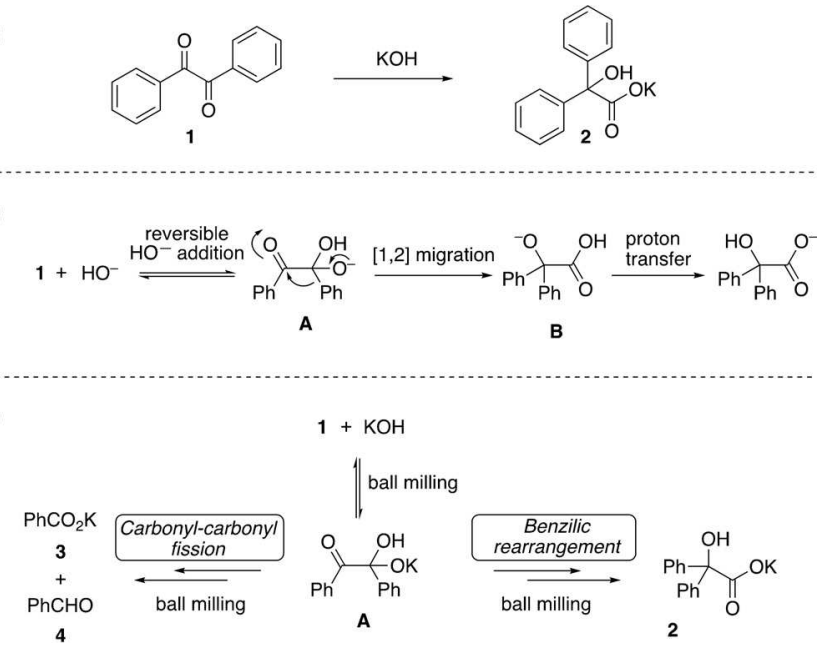

Scheme 1. a) Benzil-benzilic acid rearrangement in the presence of potassium hydroxide. b) The classically accepted mechanism for the benzil-benzilic acid rearrangement in the presence of hydroxide ions in solution. c) Mechanochemical base-induced benzilic rearrangement and base-induced carbonyl-carbonyl fission to generate products 2-4.

Since its discovery by Liebig in $1838,{ }^{[6]}$ the benzil-benzilic acid rearrangement has been in the focus of exhaustive experimental $^{[7]}$ and theoretical studies. ${ }^{[8]}$ It is generally assumed that in solution this rearrangement occurs through the initial reversible addition of a hydroxide ion to benzil, followed by an irreversible [1,2]-phenyl migration and a subsequent proton exchange (Scheme $1 \mathrm{~b}$ ). With these precedents in mind, we first wondered if a molecular rearrangement of this type could be promoted mechanochemically in the absence of solvent. Secondly, if achievable we surmised that the application of in situ monitoring techniques to the mechanochemical version of the benzil-benzilic acid rearrangement could permit the observation of some of the aforementioned mechanistic steps. And more importantly, we were interested in determining whether the molecular events during the ball milling of benzil and hydroxide ions could be any different from the mechanism and intermediate stages 
typically proposed for this rearrangement in solution. Herein, we present results that provide an unprecedented insight into the solvent-free mechanochemical benzil-benzilic acid rearrangement by ball milling.

At the outset of this study, benzil (1) $(0.95 \mathrm{mmol}), \mathrm{KOH}$ (1.0 equiv; found to contain $\mathrm{KOH} \cdot \mathrm{H}_{2} \mathrm{O}$, as detailed in the proceeding text), and two tungsten carbide balls (each weighing $2.6 \mathrm{~g}$ ) were charged inside a poly(methyl)methacrylate (PMMA) milling jar under an atmosphere of argon. Subsequently, this solid mixture was milled at $30 \mathrm{~Hz}$ in a mixer mill. Monitoring of the thermal evolution of the milling process was accomplished by using a temperature sensor embedded in the milling jar, ${ }^{[10]}$ and PXRD monitoring of the reaction was performed by synchrotron X-ray diffraction $(\lambda=0.20720 \AA$; for details, see the Supporting Information).

In the first minutes of the milling, the temperature of the reaction mixture rose less than $1.0^{\circ} \mathrm{C}$ because of dissipation of the kinetic energy of the milling assembly, until it reached a steady state in which the temperature did not change by more than $0.5^{\circ} \mathrm{C}$ over time (Figure $1 \mathrm{a}$ ). In situ PXRD monitoring of the milled mixture for 45 minutes revealed only a slight loss in intensity of diffraction signals of reactants-indicating minor amorphization-but without detectable emergence of new Bragg reflections (Figure 1a).

Challenged by this result and knowing that the kinetics of the reaction in solution is first-order both in benzil and hydroxide ion, ${ }^{[11]}$ we repeated the reaction using two equivalents of $\mathrm{KOH}$. Under these conditions, the first minutes of the milling process showed a similar thermal profile compared to the original reaction, as well as an unchanged PXRD pattern of the reactants. However, after 22 minutes of milling, an abrupt change in the PXRD pattern of the reaction mixture was recorded (Figure $1 \mathrm{~b}$ ) ${ }^{[12]}$ Such a dramatic change in diffraction signals was accompanied by a swift increase in the temperature of the reaction mixture, by approximately $2.0^{\circ} \mathrm{C}$. Further milling after this event did not induce new major changes in the product composition of the mixture, and the temperature of the reaction mixture was observed to drop and reach the same steady state as before the reaction onset in
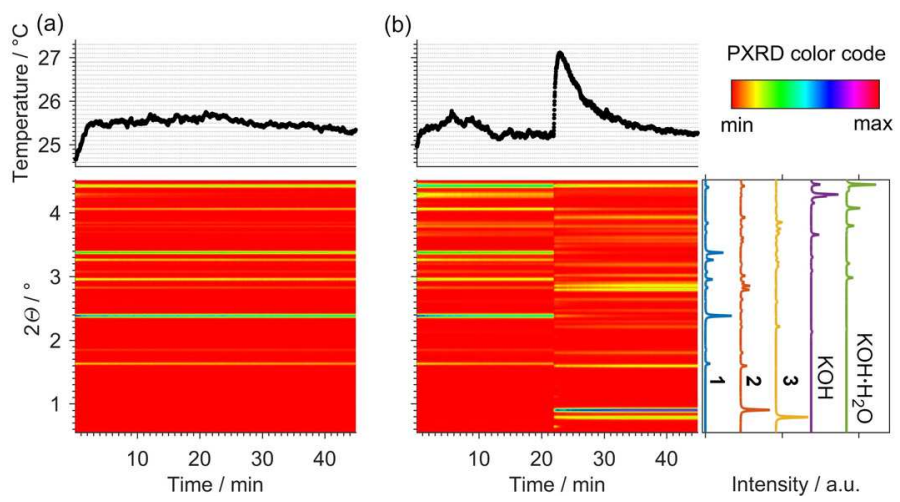

Figure 1. Time-resolved diffractograms with their temperature profiles for reactions of a) benzil (1) and $\mathrm{KOH}$ (1.0 equiv), and b) benzil (1) and $\mathrm{KOH}$ (2.0 equiv) at $30 \mathrm{~Hz}$. PXRD patterns of benzil (1), potassium benzilate (2), and potassium benzoate (3) $\mathrm{KOH}$ and $\mathrm{KOH} \cdot \mathrm{H}_{2} \mathrm{O}$ are given on the right side of the 2D plots (crystallographic data used in the PXRD analysis: 1 (BENZILO2), ${ }^{\left[{ }^{9 a}\right]} \mathbf{2}$ (KBZILT01) ${ }^{\left[{ }^{[b]}\right]} \mathbf{3}$ (VOBDUN) $,{ }^{\left[{ }^{[c]}\right]} \mathrm{KOH},{ }^{[9 \mathrm{~d}]}$ and $\mathrm{KOH} \cdot \mathrm{H}_{2} \mathrm{O}^{[9 \mathrm{ec}}$ ). the subsequent 20 minutes of milling. Rietveld analysis of the new set of Bragg reflections (Figure $1 \mathrm{~b}$ ) unequivocally proved the presence of potassium benzilate (2) as the major product, and minor amounts of potassium benzoate (3) (Supporting Information, Figures S4-S11). The former is the expected product of the benzil-benzilic acid rearrangement (Scheme 1c, right), whereas the latter is known to form as a result of a competitive carbonyl carbon-carbonyl carbon bond fission in benzil (1), which leads to potassium benzoate (3) and benzaldehyde (4) (Scheme 1c, left). ${ }^{[13]}$ Under the experimental reaction conditions (excess of $\mathrm{KOH}$ ), benzaldehyde (4) was expected to simultaneously undergo a baseinduced disproportionation through a Cannizzaro reaction, leading to the formation of additional potassium benzoate (3) and benzyl alcohol (5). Indeed, after neutralization and extraction of the reaction mixture, solution-state nuclear magnetic resonance (NMR) spectroscopy confirmed the presence of benzilic acid, benzoic acid, and trace amounts of benzyl alcohol (Supporting Information, Figures S18 and S19).

We have also observed a short-lived crystalline phase (at $0.65^{\circ}$ in $2 \Theta$ ), forming concomitantly with $\mathbf{2}$ and $\mathbf{3}$ immediately after the reaction onset, which could not be identified on the basis of a literature search, and was impossible to isolate (Supporting Information, Figures S1 and S5). Importantly, according to solution-state NMR analyses of experiments stopped before and immediately after sudden changes detected in the temperature or PXRD monitoring, the molecular rearrangement of benzil (1) coincided with the manifestation of these events. This observation was further confirmed by the analysis of the reaction mixture composition derived from the time-resolved PXRD patterns (Figure 2). Such analysis revealed how most of the benzil (1) reacted at the reaction onset while the remainder of $\mathbf{1}$ was slowly consumed toward the end of the milling experiment. $\mathrm{KOH}$ was fully consumed at the reaction onset when most of the potassium benzilate (2) and potassium benzoate (3) were formed. An increase in weight fraction of $\mathrm{KOH} \cdot \mathrm{H}_{2} \mathrm{O}$ (Figure 2, top) is an artifact of preferential amorphization of $\mathrm{KOH}$ and, to a lesser extent, of $\mathbf{1}$, as evidenced from a stable scale factor of $\mathrm{KOH} \cdot \mathrm{H}_{2} \mathrm{O}$ during milling (Figure 2, bottom). Finally, the increase in temperature at the reaction onset (Figure $1 \mathrm{~b}$ ) was ascribed to the exothermic enthalpy of formation and crystallization of $\mathbf{2}$ and $\mathbf{3}$; particularly since the temperature of the reaction mixture returned to the previous steady state. ${ }^{[8]}$

In situ monitoring of the mechanochemical benzilbenzilic acid rearrangement enabled us to visualize the moment of molecular structural change of $\mathbf{1}$ upon milling with $\mathrm{KOH}$. However, the induction time required before the rapid consumption of benzil, and the lack of observable variations in the time-resolved diffractograms, were still puzzling (Figure 1b). On the one hand, the absence of observable new Bragg reflections before the sudden molecular rearrangement of $\mathbf{1}$ could suggest the presence of very short-lived intermediates or the formation of phases lacking crystallinity, such as product nuclei that have not yet arranged into a crystalline material with phases undetectable by PXRD. On the other hand, the 

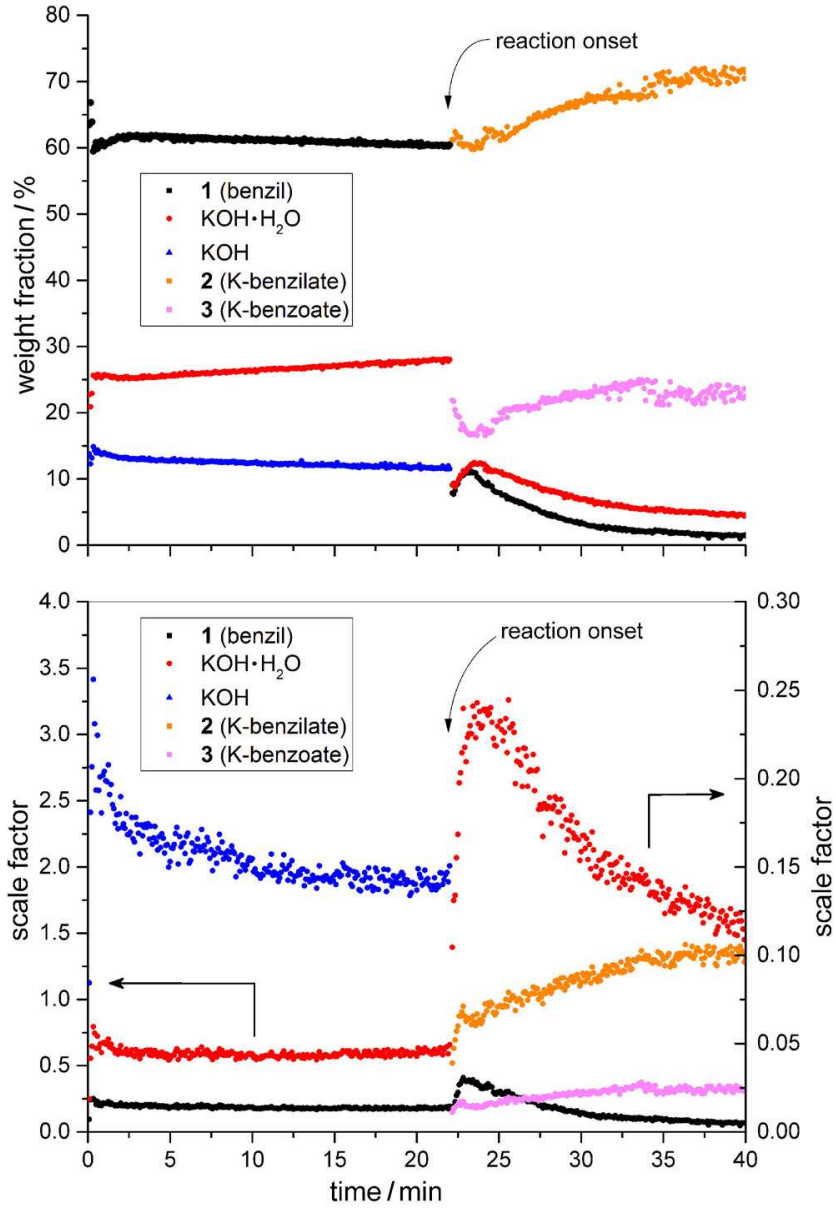

Figure 2. Top) Weight fractions. Bottom) scale factors of crystalline phases in the milling experiment using $\mathrm{KOH}$ ( 2.0 equiv). Scale factors are plotted on two different scales: left) analysis before the reaction onset; right) after the reaction occurred.

need for an induction time could indicate that the initial reduction of crystal size in the reactants by milling may be a prerequisite for the reaction to begin. ${ }^{[14]}$ Thus, $\mathbf{1}$ and $\mathrm{KOH}$ were separately milled for 30 minutes, and the ground samples were reacted. However, similar induction times compared to the standard reaction were observed, suggesting that, in this case, reaching a certain particle size of the reactants might not be the critical requirement for the rearrangement to be triggered. This is in accordance with the extracted average particle size from X-ray diffraction monitoring experiments, which do not exhibit significant differences in particle size evolution in experiments with 1.0 and 2.0 equivalents of $\mathrm{KOH}$ (Supporting Information, Figure S12). Additionally, a series of experiments were repeated and interrupted before their reaction onsets, followed by a resting period of 5 minutes to 16 hours. Once the milling was restarted (considering this moment as new time 0 ), these reactions took place faster than uninterrupted milling experiments. Similarly, cyclic milling experiments of benzil and $\mathrm{KOH}$ ( 1 min milling, 5 min pause) also promoted the benzilic rearrangement after similar total milling times compared to the standard uninterrupted reaction. These results indicate that the induction time might be related to a period required to enable proper surface contact between the reactants.

Subsequently, we evaluated whether an increase in temperature would influence the induction time for the mechanochemical benzilic rearrangement. ${ }^{[10 c, 15]}$ For this, the reaction between 1 and $\mathrm{KOH}$ (2.0 equiv) was repeated, but with an ambient laboratory temperature of approximately $27.5^{\circ} \mathrm{C}$ (compared to a previous temperature of $24.5^{\circ} \mathrm{C}$ ). The mechanochemical rearrangement of $\mathbf{1}$ was monitored in situ by Raman spectroscopy with the intention to identify the development of amorphous reactive phases or molecularlevel transformations that may have gone unnoticed during in situ X-ray diffraction monitoring (for experimental details, see the Supporting Information). Pleasingly, differences in the Raman spectra of reactants and products also enabled us to observe, in real time, the exact moment of the mechanochemical rearrangement by in situ Raman spectroscopy (Figure $3 \mathrm{a}$ ). Moreover, under these new reaction conditions (a starting temperature of ca. $27.5^{\circ} \mathrm{C}$ ) the rearrangement of benzil occurred more quickly ( $9.5 \mathrm{~min}$ vs. $22 \mathrm{~min}$; Figures $1 \mathrm{~b}$ and $3 \mathrm{a}$ ), evidencing the influence of thermal effects on the reaction by milling. ${ }^{[10,14,15]}$ However, the in-situ-collected Raman spectra did not provide evidence for the presence of new molecular species before the abrupt spectral changes related to the [1,2]-intramolecular phenyl migration (Figure $3 a)$.

As previously mentioned, solution-based experiments and computational work on the benzil-benzilic acid rearrangement have suggested an initial reversible addition of hydroxide ion to benzil that would give rise to an intermediate such as A (Scheme 1b). This step has been suggested to precede the rate-determining step involving a phenyl migration (Scheme 1b)..$^{[7,8]}$ Nonetheless, alternative mechanisms for the rearrangement of benzil (1) with hydroxide ions in solution have been proposed, in which, for example, the migration of the phenyl group and the proton transfer are concurrent rather than sequential. ${ }^{[16]}$ Similarly, the involvement of single-electron-transfer (SET) processes in the

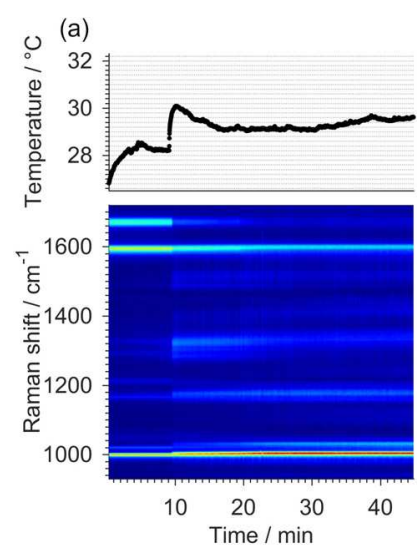

(b)

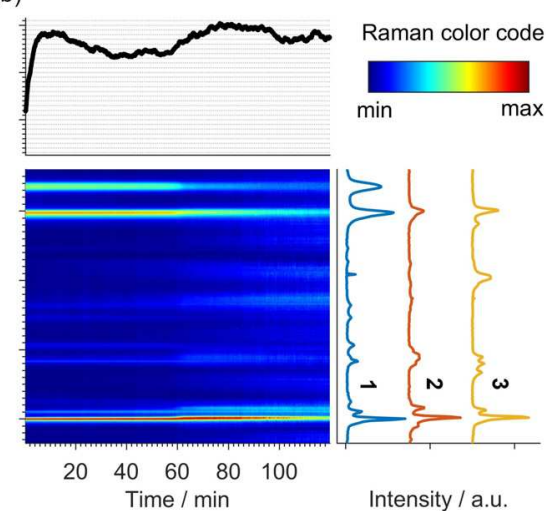

Figure 3. In situ Raman monitoring with their temperature profiles for the mechanochemical reaction of a) benzil (1) and $\mathrm{KOH}$ (2.0 equiv), and b) benzil (1) and $\mathrm{KOH}$ (1.0 equiv) at $30 \mathrm{~Hz}$. Raman spectra of benzil (1), potassium benzilate (2), and potassium benzoate (3) are given on the right side of the $2 \mathrm{D}$ plot. 
benzilic rearrangement, ${ }^{[17]}$ or the contribution of concerted pathways, have also been considered. ${ }^{[18]}$ Along these lines, the results of the in situ monitoring presented here do not provide any direct experimental evidence of the existence of intermediates such as $\mathbf{A}$ or $\mathbf{B}$ during the mechanochemical benzilic rearrangement of $\mathbf{1}$ with $\mathrm{KOH} \cdot{ }^{[19]}$ However, the identification of minor amounts of potassium benzoate (3), benzaldehyde (4), and benzyl alcohol (5) in the final reaction mixtures suggests that a short-lived common intermediate, such as $\mathbf{A}$, could have been present. We were unable to detect $\mathbf{A}$ during ball milling of $\mathbf{1}$ and $\mathrm{KOH}$; nonetheless, this could be an intermediate from which potassium benzilate (2), potassium benzoate (3), and benzaldehyde (4) could have formed (Scheme 1c). ${ }^{[8]}$

Subsequently, we investigated the apparent need for two equivalents of $\mathrm{KOH}$ to trigger the benzilic rearrangement of 1 mechanochemically (Figures $1 \mathrm{a}, \mathrm{b}$ ). Thus, a series of experiments using lesser amounts of $\mathrm{KOH}$ (that is, 1.8-1.0 equiv) was carried out. For all these cases, tandem in situ temperature and Raman monitoring of the reaction clearly showed the instant of the molecular rearrangement. Worth mentioning here was the rearrangement of $\mathbf{1}$ using an equimolar amount of $\mathrm{KOH}$, for which PXRD monitoring had not shown changes after 45 minutes of milling (Figure $1 \mathrm{a}$ ). However, monitoring of the reaction for two hours revealed that the rearrangement of $\mathbf{1}$ using one equivalent of $\mathrm{KOH}$ was equally feasible, only requiring longer milling times (Figure $3 \mathrm{~b}$ ). ${ }^{[20]}$ Analysis of the reaction mixture of this experiment by solution NMR spectroscopy confirmed the presence of potassium benzilate (2), together with traces of potassium benzoate (3). As a consequence of the smaller amounts of $\mathrm{KOH}$ used for this experiment, trace quantities of benzaldehyde (4) were also detected.

Finally, monitoring of the reaction between $\mathbf{1}$ and $\mathrm{KOH}$ ( 2.0 equiv) by temperature control and slow-motion video provided direct observation of the reaction mixture changes during ball milling (Figure 4; Supporting Information, Movie S1). In addition to the already described rise in temperature, this visual monitoring enabled us to visually identify the impressive changes happening at the exact moment of the mechanochemical transformation. These included a dramatic rheological variation in the ground reaction mixture, which became sticky, and which was accompanied by a transitory change in color. ${ }^{[21]}$ The initial pale yellow color of the mixture $(\mathbf{1}+\mathrm{KOH})$ became deep pink at the precise moment when the mechanochemical baseinduced molecular rearrangement and the $\mathrm{C}-\mathrm{C}$ bond fission of 1 took place. Subsequently, the shade of the solid reaction mixture changed over a few minutes until reaching a cream color, while the reaction mixture returned to being a freeflowing powder (Figure 4).

In summary, we have demonstrated that the iconic benzilbenzilic acid rearrangement in the presence of hydroxide ions can be accomplished in the solid state by mechanochemistry. Experimentally, a combination of real-time in situ synchrotron PXRD, Raman spectroscopy, and temperature monitoring during the ball-milling process enabled the visualization of the exact instant of the [1,2]-intramolecular phenyl migration in benzil (1). Furthermore, while the continuous monitoring

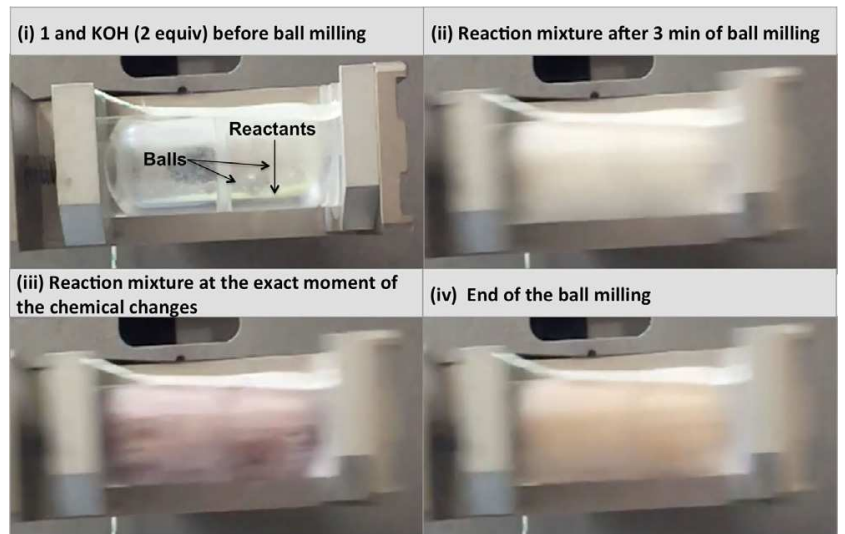

Figure 4. Photographs of i) the PMMA milling jar showing $1, \mathrm{KOH}$, and the milling balls before the ball milling; ii) the milling jar during the first part of the ball-milling process; iii) the reaction mixture during the moment of the chemical changes; iv) the milling vessel before the ball milling was halted.

of the reaction did not evidence the emergence of intermediates before the rapid structural changes underwent by $\mathbf{1}$, the background base-induced $\mathrm{C}-\mathrm{C}$ bond fission of $\mathbf{1}$ without migration of a phenyl group could have occurred from a commonly shared tetrahedral adduct intermediate, such as A. Finally, from a general perspective, the results of this study inform us of the feasibility of molecular rearrangements to proceed mechanochemically in the absence of solvent. Moreover, this study reinforces the utility of implementing in situ monitoring techniques to gain a deeper understanding of the mechanistic details occurring upon activation of organic systems under the exertion of mechanical forces.

\section{Acknowledgements}

C.B. and J.G.H. are grateful to RWTH Aachen University for financial support through the Distinguished Professorship Program funded by the Excellence Initiative of the German Federal and State Governments. K.U. acknowledges support from the European Social Fund and the Croatian Science Foundation (PZS-2019-02-4129). S.L. is supported by the Croatian Science Foundation. We thank Dr. N. Biliškov, T. Stolar, and Dr. B. Karadeniz (Ruđer Bošković Institute) for technical assistance.

\section{Conflict of interest}

The authors declare no conflict of interest.

Keywords: benzilic rearrangement · in situ studies . mechanochemistry $\cdot$ Raman spectroscopy $\cdot$ X-ray diffraction

[1] For selected recent Reviews, see: a) C. Bolm, J. G. Hernández, Angew. Chem. Int. Ed. 2019, 58, 3285-3299; Angew. Chem. 2019, 131, 3320-3335; b) T. Friščić, C. Mottillo, H. M. Titi, Angew. Chem. Int. Ed. 2020, 59, 1018-1029; Angew. Chem. 2020, 132, 1030-1041; c) D. Tan, F. García, Chem. Soc. Rev. 
2019, 48, 2274-2292; d) C. G. Avila-Ortiz, M. Pérez-Venegas, J. Vargas-Caporali, E. Juaristi, Tetrahedron Lett. 2019, 60, 17491757; e) J. L. Howard, Q. Cao, D. L. Browne, Chem. Sci. 2018, 9 , 3080-3094; f) C. Bolm, J. G. Hernández, ChemSusChem 2018 11, 1410-1420; g) J. Andersen, J. Mack, Green Chem. 2018, 20, 1435-1443; h) J. G. Hernández, Chem. Eur. J. 2017, 23, $17157-$ 17165 ; i) N. R. Rightmire, T. P. Hanusa, Dalton Trans. 2016, 45 , $2352-2362 ;$ j) J.-L. Do, T. Friščić, ACS Cent. Sci. 2017, 3, 13-19; k) J. G. Hernández, C. Bolm, J. Org. Chem. 2017, 82, 4007-4019.

[2] a) M. Ferguson, M. S. Moyano, G. A. Tribello, D. E. Crawford E. M. Bringa, S. L. James, M. G. Del Pópolo, Chem. Sci. 2019, 10, 2924-2929; b) M. F. Pill, A. L. L. East, D. Marx, M. K. Beyer, H Clausen-Schaumann, Angew. Chem. Int. Ed. 2019, 58, 9787 9790; Angew. Chem. 2019, 131, 9890-9894; c) A. E. M Beedle, M. Mora, C. T. Davis, A. P. Snijders, G. Stirnemann, S. Garcia-Manyes, Nat. Commun. 2018, 9, 3155.

[3] a) T. Friščić, I. Halasz, P. J. Beldon, A. M. Belenguer, F. Adams, S. A. J. Kimber, V. Honkimäki, R. E. Dinnebier, Nat. Chem. 2013, 5, 66-73; b) I. Halasz, A. Puškarić, S. A. J. Kimber, P. J. Beldon, A. M. Belenguer, F. Adams, V. Honkimäki, R. E. Dinnebier, B. Patel, W. Jones, V. Štrukil, T. Friščić, Angew. Chem. Int. Ed. 2013, 52, 11538-11541; Angew. Chem. 2013, 125 , $11752-11755$; c) D. Gracin, V. Štrukil, T. Friščić, I. Halasz, K. Užarević, Angew. Chem. Int. Ed. 2014, 53, 6193-6197; Angew. Chem. 2014, 126, 6307-6311; d) L. Batzdorf, F. Fischer, M. Wilke, K.-J. Wenzel, F. Emmerling, Angew. Chem. Int. Ed. 2015 54, 1799-1802; Angew. Chem. 2015, 127, 1819-1822; e) A. D. Katsenis, A. Puškarić, V. Štrukil, C. Mottillo, P. A. Julien, K. Užarević, M.-H. Pham, T.-O. Do, S. A. J. Kimber, P. Lazić, O. Magdysyuk, R. E. Dinnebier, I. Halasz, T. Friščić, Nat. Commun. 2015, 6, 6662; f) K. Užarević, I. Halasz, T. Friščić, J. Phys. Chem. Lett. 2015, 6, 4129-4140; g) P. A. Julien, K. Užarević, A. D. Katsenis, S. A. J. Kimber, T. Wang, O. K. Farha, Y. C. Zhang, J. Casaban, L. S. Germann, M. Etter, R. E. Dinnebier, S. L. James, I. Halasz, T. Friščić, J. Am. Chem. Soc. 2016, 138, 2929-2932; h) S. Lukin, T. Stolar, M. Tireli, M. V. Blanco, D. Babić, T. Friščić, K. Užarević, I. Halasz, Chem. Eur. J. 2017, 23, 13941 13949; i) T. Stolar, L. Batzdorf, S. Lukin, D. Žilić, C. Motillo, T. Friščić, F. Emmerling, I. Halasz, K. Užarević, Inorg. Chem. 2017, 56, 6599-6608; j) K. Užarević, N. Ferdelji, T. Mrla, P. A. Julien, B. Halasz, T. Friščić, I. Halasz, Chem. Sci. 2018, 9, 2525-2532; k) M. Wilke, N. Casati, Chem. Eur. J. 2018, 24, 17701-17711; 1) T. Stolar, S. Lukin, M. Tireli, I. Sović, B. Karadeniz, I. Kereković, G. Matijašić, M. Gretić, Z. Katančić, I. Dejanović, M. di Michiel, I. Halasz, K. Užarević, ACS Sustainable Chem. Eng. 2019, 7, 7102-7110; m) S. Lukin, M. Tireli, T. Stolar, D. Barišić, M. V. Blanco, M. di Michiel, K. Užarević, I. Halasz, J. Am. Chem. Soc. 2019, 141, 1212-1216.

[4] For selected examples, see: a) S. Lukin, M. Tireli, I. Lončarić, D. Barišić, P. Šket, D. Vrsaljko, M. di Michiel, J. Plavec, K. Užarević, I. Halasz, Chem. Commun. 2018, 54, 13216-113219; b) H. Kulla, S. Haferkamp, I. Akhmetova, M. Rölling, C. Maierhofer, K. Radenmann, F. Emmerling, Angew. Chem. Int. Ed. 2018, 57, 5930-5933; Angew. Chem. 2018, 130, 6034-6038; c) S. Haferkamp, W. Kraus, F. Emmerling, J. Mater. Sci. 2018, 53, $13713-13718$; d) P. A. Julien, I. Malvestiti, T. Friščić, Beilstein J. Org. Chem. 2017, 13, 2160-2168; e) S. Haferkamp, A. Paul, A. A. L. Michalchuk, F. Emmerling, Beilstein J. Org. Chem. 2019, 15, 1141-1148.

[5] For selected examples, see: a) M. Tireli, M. Juribašić Kulcsár, N. Cindro, D. Gracin, N. Biliškov, M. Borovina, M. Ćurić, I. Halasz, K. Užarević, Chem. Commun. 2015, 51, 8058-8061; b) V. Štrukil, D. Gracin, O. V. Magdysyuk, R. E. Dinnebier, T. Friščić, Angew. Chem. Int. Ed. 2015, 54, 8440-8443; Angew. Chem. 2015, 127, 8560-8563.
[6] J. von Liebig, Justus Liebigs Ann. Chem. 1838, 25, 27.

[7] A. J. Burke, C. S. Marques, Mini. Rev. Org. Chem. 2007, 4, $310-$ 316.

[8] a) N. Sultana, W. M. F. Fabian, Beilstein J. Org. Chem. 2013, 9, 594-601; b) S. Yamabe, N. Tsuchida, S. Yamazaki, J. Org. Chem. 2006, 71, 1777-1783; c) I. Lee, D. Lee, J. K. Lee, C. K. Kim, B.-S. Lee, J. Chem. Soc. Perkin Trans. 2 1996, 2519-2523.

[9] a) E. J. Gabe, Y. Le Page, F. L. Lee, L. R. C. Barclay, Acta Crystallogr. Sect. B 1981, 37, 197-200; b) L. S. Rojas, B. M. Ramírez, A. J. Mora, G. E. Delgado, G. D. de Delgado, Acta Crystallogr. Sect. E 2003, 59, m647-m651; c) C. Butterhof, T. Martin, W. Milius, J. Breu, Z. Anorg. Allg. Chem. 2013, 639, 2816-2821; d) H. Jacobs, J. Kockelkorn, T. Tacke, Z. Anorg. Allg. Chem. 1985, 531, 119-124; e) J. Clastre, Cah. Phys. 1956, $74,24-25$.

[10] The milling jar had a small aluminum pin $(3 \mathrm{~mm}$ height, $2 \mathrm{~mm}$ diameter) embedded into the jar wall and in direct contact with the inside of the jar. A thermocouple was then placed in thermal contact with the pin. For recent studies on temperature development and temperature control in ball milling, see: a) $\mathrm{K}$. Užarević, N. Ferdelji, T. Mrla, P. A. Julien, B. Halasz, T. Friščić, I. Halasz, Chem. Sci. 2018, 9, 2525-2532; b) H. Kulla, M. Wilke, F. Fischer, M. Rölling, C. Maierhofer, F. Emmerling, Chem. Commun. 2017, 53, 1664-1667; c) N. Cindro, M. Tireli, B. Karadeniz, T. Mrla, K. Užarevic, ACS Sustainable Chem. Eng. 2019, 7, 16301-16309; d) J. Andersen, J. Mack, Angew. Chem. Int. Ed. 2018, 57, 13062-13065; Angew. Chem. 2018, 130, 1324613249.

[11] a) F. H. Westheimer, J. Am. Chem. Soc. 1936, 58, 2209-2214; b) S. Selman, J. F. Eastham, Quart. Rev. 1960, 14, 221-235.

[12] A posterior experiment under similar conditions (scale, stoichiometry, milling media, milling frequency, and initial temperature) showed the same chemical changes after $19.5 \mathrm{~min}$ of milling.

[13] a) K. Bowden, W. M. F. Fabian, J. Phys. Org. Chem. 2001, 14, $794-796$; b) K. Bowden, K. D. Williams, J. Chem. Soc. Perkin Trans. 2 1994, $77-81$.

[14] A. M. Belenguer, A. A. L. Michalchuk, G. I. Lampronti, J. K. M. Sanders, Beilstein J. Org. Chem. 2019, 15, 1226-1235.

[15] K. Užarević, V. Štrukil, C. Mottillo, P. A. Julien, A. Puškarić, T. Friščić, I. Halasz, Cryst. Growth Des. 2016, 16, 2342-2347.

[16] M. T. Clark, E. C. Hendley, O. K. Neville, J. Chem. Soc. 1955, 77, $3280-3284$.

[17] a) C. G. Screttas, M. Micha-Screttas, C. T. Cazianis, Tetrahedron Lett. 1983, 24, 3287-3288; b) I. Rajyaguru, H. S. Rzepa, J. Chem. Soc. Perkin Trans. 2 1987, 1819-1827; c) F. Toda, K. Tanaka, Y. Kagawa, Y. Skaino, Chem. Lett. 1990, 19, 373-376.

[18] D. G. Ott, G. G. Smith, J. Am. Chem. Soc. 1955, 77, 2325-2329.

[19] Milling experiments of $\mathbf{1}$ and KOH in the presence of TEMPO (2,2,6,6-tetramethyl-1-piperidinyloxy free radical; 2.5$100 \mathrm{~mol} \%$ ) still promoted the mechanochemical rearrangement of $\mathbf{1}$. Analysis of the milled reaction mixture by NMR and highresolution mass spectrometry (HRMS) did not reveal the presence of detectable TEMPO adducts.

[20] T. W. Evans, W. M. Dehn, J. Am. Chem. Soc. 1930, 52, 252-254.

[21] For physical changes commonly occurring in organic mechanochemical reactions, see: G. Rothenberg, A. P. Downie, C. L. Raston, S. L. Scott, J. Am. Chem. Soc. 2001, 123, 8701-8708.

Manuscript received: November 22, 2019

Revised manuscript received: March 18, 2020

Accepted manuscript online: March 18, 2020

Version of record online: June 3, 2020 